\title{
DISCUSSÕES TEÓRICAS ACERCA DA PRÁTICA EDUCATIVA NO CAMPO
}

Resenha do livro:

SANTOS, Cláudio Félix dos. O "aprender a aprender" na formação de professores do campo. Campinas, SP: Editora Autores Associados; Edições UESB: Vitória da Conquista, BA, 2013.

Resenha de:

Urânia T. Amaral ${ }^{1}$

Tânia Maria Rodrigues da Rocha ${ }^{2}$

O livro "aprender a aprender" na formação de professores do campo é de autoria do Prof. Dr. Cláudio Félix dos Santos. O tema discutido pelo autor é fruto de sua tese de doutorado defendida na Universidade Federal da Bahia (UFBA), no ano de 2011.

O livro analisa as influências da ideologia pós-moderna e as propostas de formação de professores do campo, tendo como destaque os movimentos sociais ocorridos em meados de 1980. O autor afirma logo no primeiro capítulo, que o pós-modernismo surgiu na chamada "fase de ouro do capitalismo", entre as décadas de 1950 e 1970, período próspero para os países capitalistas centrais, com a interferência estatal na economia. Naquela época, segundo ele, havia certo conformismo por parte de grandes parcelas da direção da classe operária, a qual se acomodava diante os encantos do capitalismo na sua fase de "bem-estar social". Porém, em meados de 1968, os movimentos de juventude, ocorridos em maio deste mesmo ano, se colocavam contrários tanto das relações sociais capitalistas quanto da repressão burocrática do aparelho stalinista com influências no movimento comunista no mundo inteiro. Em suma, o autor sintetiza o pensamento pósmodernista segundo um conjunto de tendências intelectuais e políticas que se fundamentam na crise do capitalismo imperialista.

Ainda no primeiro capítulo o autor faz uma abordagem sobre as perspectivas do escolanovismo que se contrapõe aos pressupostos epistemológicos da pedagogia da escola tradicional. A ideia da escola nova é a de romper com os mecanismos tradicionais, que se resumem em aulas onde há apenas a mera transmissão de conteúdos. A proposta é então desenvolver atividades interativas que induza nos estudantes a vontade de estar na escola. O "autoritarismo" da antiga escola deveria ser extinto, e substituído por uma metodologia mais espontânea, que estimule no educando a autonomia, a pensar livremente e construir suas opiniões, tornando-se assim um cidadão melhor articulado ao novo momento do capitalismo o qual necessitava de cidadãos mais proativos, criativos, inovadores. É dai que nasce o termo elencado pelo autor "aprender a aprender", um novo modelo de educação, no qual os indivíduos aprendem por si mesmos, e devem ser estimulados a produzir seu próprio conhecimento. Tal proposta enfatiza a relevância em relacionar os conteúdos com a vivência do educando. O professor precisa desenvolver competências dentro da sua própria prática enquanto educador. Desse modo, a principal finalidade da escola nova seria desenvolver um formato em que haja boas relações entre os indivíduos, em que os professores se preocupem principalmente em proporcionar uma aprendizagem conforme os interesses dos alunos, e não somente com o ensino.

Em relação à formação de professores, o autor ressalta que, segundo os princípios escolanovistas, para haver uma formação adequada desses profissionais é imprescindível que os mesmos, desde o primeiro semestre do curso, já tenham uma prática pedagógica em sala de aula, e assim, a partir dos obstáculos enfrentados na própria vivência possa refletir 
e repensar sua metodologia, a fim de criar meios de tornar suas aulas mais criativas e prazerosas.

O autor menciona as diversas formas de reflexão que o professor pode desenvolver na sua prática educativa e encerra o primeiro capitulo afirmando que este modelo pragmático de formação profissional está ligado há uma proposição hegemônica que visa apenas à profissionalização do individuo para adquirir um emprego, sendo o conhecimento prático e as competências adquiridas os meios mais eficazes para encontrar um lugar ao sol no concorrido mercado.

No segundo capítulo, o autor faz uma abordagem sobre os movimentos que lutam pela educação no campo, não apenas como um movimento de reivindicação pelo acesso à escolarização, mas, como uma educação constituída por uma teoria pedagógica fundamentada, em especial, na educação popular e na pedagogia da prática. Além dessa abordagem, foi feito um levantamento de como surgiu à educação no campo, sendo que o primeiro movimento ocorreu em 1920, chamado de ruralismo pedagógico. Mas, os latifundiários só apoiaram este movimento porque pretendiam manter o homem no campo, a fim de não perder a mão de obra. Outros movimentos foram ocorrendo, e contribuíram para que houvesse alterações nos processos educativos.

Sobre a pedagogia da educação popular, de acordo com o pensamento freiriano, pleiteia-se uma pedagogia libertadora, preocupada com as classes de baixa renda em contraposição àquela que era restrita a elite. Ao falar sobre esta pedagogia o autor destaca o pensamento de Paulo Freire acerca da relação entre o opressor e o oprimido. A prática pedagógica libertadora acontece por meio de uma conscientização da realidade em que os oprimidos vivem, a fim de que os mesmos possam lutar contra opressão. Ao falar sobre as pedagogias da prática, o autor faz uma abordagem sobre o pensamento de Miguel Arroyo. O princípio dessa teoria parte de um método que busque nas experiências da prática cotidiana dos movimentos sociais, da cultura, a forma de construir uma escola voltada para classe trabalhadora. $\mathrm{O}$ processo de aprendizagem acontece pela própria prática das lutas dos movimentos sociais, toda a vivência que os indivíduos perpassam, faz com eles adquiram saberes, valores que geralmente são menosprezados pela ciência.

Ainda no capitulo, o autor aborda algumas experiências educativas do movimento por uma educação do campo, a saber: a proposição do Movimento dos Trabalhadores Rurais Sem Terra (MST), A Pedagogia da Alternância e a Educação para a Convivência com o Semiárido.

O movimento dos trabalhadores rurais sem terra (MST) defende uma educação para além da escola. Para estes trabalhadores a educação está pautada na luta contra o latifúndio e o capitalismo, em favor dos valores socialistas e humanistas. Eles não são contra o modelo de educação formal, mas lutam por uma forma de educar que se preocupe com a realidade vivenciada pelos mesmos.

O autor ainda relata sobre a pedagogia da alternância, em que a educação não se baseia na formalidade, mas na construção do conhecimento tanto na escola quanto no meio familiar. São monitores que executam o trabalho educativo interagindo com a comunidade e sob a direção de uma associação local. Algumas experiências e princípios da Pedagogia de Alternância foram assumidos pelo Programa Nacional de Educação na Reforma Agrária (Pronera) e pelo Ministério da Educação (MEC), no sentido de desenvolver uma política de educação diferenciada para o meio rural. A formação do sujeito deve ser voltada para a realidade no campo, tendo em vista a melhoria de vida no meio rural tanto nos âmbitos socioeconômico, político, cultural, técnico - cientifico e, sobretudo, sustentável.

Assim, como é relatado, há divergências no entendimento de qual seria a melhor forma de educação, uns vão dar crédito para os saberes locais de sua cultura, outros 
consideram os movimentos sociais como modelo concreto de educação. Em sua maioria defendem uma educação para além da escola.

Sobre a Licenciatura em educação no campo (LEC), o autor, após um estudo crítico acerca da interdisciplinaridade na perspectiva escolanovista e construtivista conclui que essa concepção pode não apresentar possibilidades verdadeiramente transformadoras para o enfrentamento dos problemas da fragmentação disciplinar e da prática pedagógica escolar. De qualquer forma essa formação de professores no campo é uma conquista, a qual contribuiu para enriquecer as práticas educativas assim como dar subsidio para fundamentar os trabalhadores na atuação dos movimentos sociais e práticas agrícolas.

Assim, no que se diz respeito a essa educação no campo, deve-se ater para a questão da política educacional, que em seu turno, ainda não conseguiu solucionar os problemas que afetam a educação, especificamente em relação à qualidade de ensino, estrutura física, ausência de políticas e a formação de professores. As propostas pedagógicas são inúmeras, e também não se podem negar os programas e ações criados especificamente para a educação no campo. No entanto, o que se percebe é que as teorias com as práticas não estão sendo executadas nas escolas do campo de forma eficiente. Por fim, é necessário rever qual seria a melhor forma pedagógica de educação no campo.

O autor faz uma crítica radical aos princípios do "aprender a aprender", ao enfatizar a importância da existência escolar, sob uma perspectiva da pedagogia histórico-critica. Ele destaca que o cotidiano pode estar presente na prática educativa, porém deve ser atrelado a uma construção histórica. Salienta-se que é preciso dar credito a ciência e a universalização da cultura na educação escolar, ao desconsiderar estes estudos na escola traz consequências para a própria luta de classes. Com isso a classe trabalhadora fica destituída de uma formação teórico-cientifica, tornando difícil a sua organização enquanto classe. Visto isso o autor deixa claro que a escola pode contribuir para que a classe trabalhadora lute contras as diversas formas de dominação e exploração impostas pelo sistema capitalista.

No quinto capítulo o autor discute sobre a prática da pedagogia histórico-critica em contraponto com as propostas dos marcos da pedagogia do "aprender a aprender", sobre a formação do professor por área do conhecimento. Ele reitera que ao invés de formar o professor por área é importante dar uma fundamentação teórica tendo em vista as condições sociais e econômicas brasileiras, os desafios enfrentados no campo e na cidade. Assim o autor encerra suas discussões dando enfoque a relevância de desenvolver uma educação cheia de conteúdos que contribuam para uma formação adequada, por meio de práticas de auto-organização. E por fim, afirma que tais questões não se esgotam nesta obra, mas requer avanços em estudos e debates em torno da formação de professores do campo.

\section{Notas}

\footnotetext{
${ }^{1}$ Graduada em Licenciatura Plena em Geografia pela Universidade Estadual do sudoeste da Bahia (UESB). Mestranda em Memória: Linguagem e Sociedade pelo Programa de Pós-Graduação (UESB) e pesquisadora do grupo de pesquisa Museu Pedagógico: História, Trabalho e Educação.

${ }^{2}$ Graduada em Ciências Econômicas. Mestranda em Memória, Linguagem e Sociedade pelo Programa de Pós-Graduação (UESB) e pesquisadora do grupo de pesquisa Museu Pedagógico: História, Trabalho e Educação.
} 